\section{Other Topics}

\section{HTMC- $X$ in 2000}

Hilpert reported that the conference will be held at Jülich from 10-14 April 2000 (Monday-Thursday). Mail asking for IUPAC sponsorship was sent to Jost, and HTMC$\mathrm{X}$ has been announced in Chemistry International as approved. An international advisory committee has been established. Plenary lectures are foreseen as covering general overviews of alloys, ceramics, thermodynamic modeling, and CVD (coatings). Keynote lectures will be delivered by younger scientists. A visit to Jülich KFA laboratories will be arranged for Friday, 15 April. Hands-on demonstrations of thermodynamic databases will be organized. A proceedings volume may be issued by the Jülich Institute. The first circular will be issued shortly, and the conference will be announced in materials-related journals.

HTMC-XI in 2003

Rosenblatt reported that he will contact prospective organizers within months. The actual deadline for determining the location of HTMC-XI is the HTMC-X meeting in April 2000 (see above).
Commission II.3 Meeting in 1999

The commission meeting will be during the General Assembly in Berlin, 7-14 August.

\section{Report from CTC}

Kizilyalli reported. CTC Chairman Bradley summarized the future actions and some dilemmas at the CTC meeting in Geneva. His observations were distributed to Commission II.3 members. CTC launched an international critical review of chemical education, with the important objective of providing the basis for transmitting chemical principles into associated disciplines, such as materials chemistry and chemical biology. The plan is to produce approximately 10 manuscripts on suitable subjects and publish them by June 1999. CTC will work out the details of a formal agreement with UNESCO to secure funding for this project. Comments concerning this action are solicited.

\section{Kolar}

Secretary of Commission II.3

\title{
Prizes and Awards
}

\section{Maison de la Chimie Foundation Prize}

This prestigious award, created in 1986, is intended to honor an original work in chemistry of benefit to mankind, society, or nature. The year 2000 prize, to be awarded to one or several recipients, irrespective of nationality, has a value of $150,000 \mathrm{FF}$.

All entries must be presented through a learned society or through a national or international scientific organization, such as IUPAC. Entry forms, a report on the work of candidates, and copies of the most significant publications related to this work must be registered by the Secretariat of the Maison de la Chimie Foundation before 15 May 1999. Entries will be judged by an international jury composed of a chairman and 10 prominent members recognized for their work in chemistry. The jury for the year 2000 prize includes

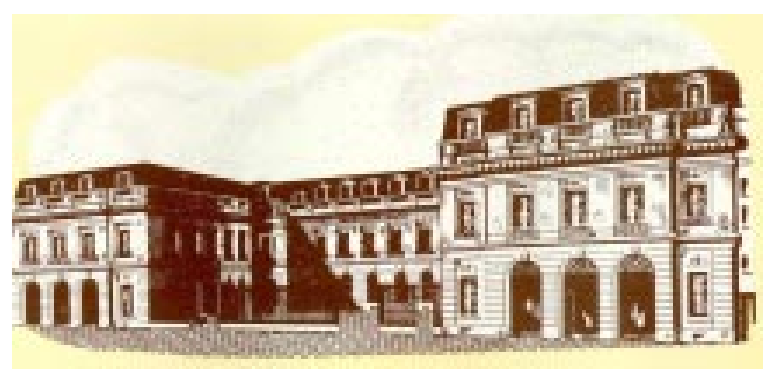

three former laureates (Peter B. Dervan, Professor of Chemistry, California Institute of Technology, Pasadena, CA, USA, 1996; Claude Helene, Membre de l'Institut, Professeur au Museum National d'Histoire Naturelle, Directeur Scientifique du Groupe RhonePoulenc, 1996; and Professor Herbert W. Roesky, Institut fur Anorganische Chemie der Universitat Gottingen, 1998), and six scientists whose nationality is other than French. The jury will choose the prize winner by majority vote, and the laureate will be invited to present a lecture on his or her work at the award ceremony on 18 January 2000 at the Maison de la Chimie in Paris. Unsuccessful entries may be renewed for subsequent awards of the prize.

For entry forms or additional information, contact the Secretariat, Prix de la Fondation de la Maison de la Chimie, 28, rue Saint-Dominique, 75341 Paris Cedex 07, France, Tel: 01406227 00; Fax: 0140629521.

\section{King Faisal International Prize}

The 1999 winners of the annual King Faisal International Prize (KFIP) for Science (Chemistry) and Medicine (Allergic Diseases) have been announced in Riyadh, Saudi Arabia.

Professors Ryoji Noyori (Chemistry Department, Nagoya University, Nagoya, Japan) and Dieter Seebach 